\title{
Vibrational Spectroscopy as a Tool for Examination to the Secondary Structure of Metal-labeled Trastuzumab Immunoconjugates
}

\author{
Sterjova M. ${ }^{1,2}$, Džodić P. ${ }^{2}$, Makreski P. ${ }^{3}$, Duatti A. ${ }^{4}$, Risteski M ${ }^{5}$, Janevik-Ivanovska E. \\ Correspondent $^{1}$
}
${ }^{1}$ Goce Delčev University, Faculty of Medical Sciences, str. "Krste Misirkov" No. 10-A, 2000 Štip, Republic of Macedonia
${ }^{2}$ University of Niš, Faculty of Medicine, Department of Pharmacy, str. dr Zoran Đindić 81, 18000 Niš, Serbia
${ }^{3}$ Institute of Chemistry, Faculty of Natural Sciences and Mathematics, Ss. Cyril and Methodius University, 1000 Skopje, Republic of Macedonia
${ }^{4}$ University of Ferrara, Department of Chemical and Pharmaceutical Sciences, Ferrara 44121, Italy
${ }^{5}$ University Clinic of Radiotherapy and Oncology, str. Vodnjanska 17, 1000 Skopje, Republic of Macedonia

\begin{abstract}
Infrared and Raman spectroscopy are effective techniques that allow collecting information about secondary structure of proteins, including antibodies.

Trastuzumab, antibody used in our study was in a freeze-dried form, conjugated with different bifunctional chelators and linked with the stable isotopes of lutetium and yttrium. The characterization of the final immunoconjugates showed no significant changes in the structure demonstrated by the presence of the amide bands characteristic for a $\alpha$-helices and $\beta$-sheets structures.

These methods could be applied during the production of the antibody freeze-dried kit formulations for the labeling with the radioactive isotopes.
\end{abstract}

\section{Keywords}

Trastuzumab, Freeze-drying, Infrared spectroscopy, Raman spectroscopy, Bifunctional chelators, Yttrium and Lutetium. 